\title{
Effect of homologous and heterologous seminal plasma on the fertilizing ability of ejaculated bull spermatozoa assessed by penetration of zona-free bovine oocytes
}

\author{
M. A. Henault and G. J. Killian* \\ Dairy Breeding Research Center, Department of Dairy and Animal Science, \\ The Pennsylvania State University, Universily Park, PA 16802, USA
}

\begin{abstract}
The ability of seminal plasma to influence the fertility of ejaculated bull spermatozoa was examined using a sperm penetration assay for zona-free bovine oocytes. Washed, ejaculated spermatozoa from bulls of below (low) or above average (high) fertility were mixed with seminal plasma from the same bull, or with seminal plasma from a bull of contrasting fertility. Treated spermatozoa were stained with different fluorochromes and competed to penetrate oocytes after heterospermic insemination in vitro. Washed spermatozoa exposed to seminal plasma from bulls of high fertility penetrated more oocytes than those spermatozoa mixed with seminal plasma from bulls of low fertility $(P<0.01)$. Mixing low fertility spermatozoa with high fertility seminal plasma generally improved penetrating ability compared with low fertility spermatozoa mixed with low fertility seminal plasma $(P=0.05)$. Washed spermatozoa from a bull of low fertility mixed with his own seminal plasma had greater ability to penetrate oocytes than did washed spermatozoa from a bull of high fertility mixed with seminal plasma from a bull of low fertility $(P<0.01)$. The bias associated with using low fertility seminal plasma from the bull providing the spermatozoa was removed by repeating this experiment using pooled seminal plasma from different subfertile bulls. After combination with pooled seminal plasma from bulls of low fertility spermatozoa from bulls of high or low fertility penetrated oocytes in a similar way, but high fertility spermatozoa had a slightly higher penetration rate $(P=0.12)$. In conclusion, the penetration of zona-free oocytes by ejaculated spermatozoa from bulls of low fertility was marginally improved by seminal plasma from bulls of high fertility, but penetration by high fertility spermaotoza was decreased by exposure to low fertility seminal plasma. Seminal plasma from bulls of low fertility similarly affected the penetrating ability of high and low fertility spermatozoa if the seminal plasma used was foreign to the spermatozoa being tested.
\end{abstract}

\section{Introduction}

Suboptimal fertility in males is a concern in humans and in agricultural animals. Although males typically labelled as subfertile or infertile are characterized by poor sperm motility, high numbers of abnormal spermatozoa or spermatozoa with inadequate freezability, the subfertile male with normal semen parameters remains an enigma. For these males, the factors contributing to their subfertility are largely unknown.

Collectively, the various studies comparing the effects of seminal plasma on the fertility of caudal or ejaculated spermatozoa are inconclusive. Mouse and rabbit spermatozoa become more fertile after the addition of a low molecular mass factor from human seminal plasma (Gaur and Talwar, 1973, 1975). Seminal plasma components, especially those from the seminal

*Corresponding author.

Revised manuscript received 29 May 1996. vesicles, augment fertility in rats (Curry and Atherton, 1990). Changes in composition of seminal plasma resulting from removal of some or all of the accessory sex glands may also be detrimental to fertility in rats (Queen et al., 1981), hamsters (Chow et al., 1986) and mice (Pang et al., 1979).

In contrast, several studies have concluded that exposure of spermatozoa to seminal plasma depressed sperm motility in boars (Iwamoto et al., 1992), humans (Iwamoto and Gagnon, 1988), bulls, rams, goats (Dott et al., 1979; Corteel, 1980), stallions and rabbits (Corteel, 1980). Decreases in sperm fertility after exposure to seminal plasma components have also been reported for humans (Audhya et al., 1987) and rabbits (Chang, 1957).

Studies evaluating the seminal plasma characteristics of individuals and their relationship to fertility are limited. When compared to fertile men, infertile men have missing seminal plasma proteins as resolved by two-dimensional gel electrophoresis (Sadowski and Rogers, 1985). Protein profiles in 
two-dimensional gels have also been found to differ between seminal plasma from bulls of high or low fertility (Killian et al., 1993), as has the distribution of heparin-binding protein (Kandell et al., 1992). The presence, absence or the critical concentration of proteins in seminal plasma could potentially be responsible for the effects of seminal plasma or sperm fertility.

One difficulty with previous studies that attempted to establish the effect of seminal plasma on animal fertility was the lack of adequate fertility data on the individuals studied. In addition, relatively small effects of seminal plasma on fertility may escape detection because of insensitivity of the assay. The studies described in this paper overcome these potential problems by using cull dairy bull sires with reliable fertility data, and by using a heterospermic zona-free bovine oocyte penetration assay which negates the effect of variation in eggs and facilitates the detection of small differences in penetration rates.

Previously, we found that the ability of cauda epididymal spermatozoa from bulls of low fertility to penetrate oocytes could be improved significantly by exposure to fluid from the accessory glands of bulls of high fertility (Henault et al., 1995). The aim of the present study was to determine whether the penetration rates of zona-free oocytes by ejaculated spermatozoa in vitro could be altered by exposure to seminal plasma from a bull of contrasting fertility.

\section{Materials and Methods}

\section{Experimental strategy}

The effect of exposure to seminal plasma from a bull of contrasting fertility on the fertility of ejaculated spermatozoa was determined by washing spermatozoa from one bull and incubating the spermatozoa with either his own (homologous) seminal plasma or seminal plasma from another bull (heterologous) of contrasting fertility. These differently treated spermatozoa were stained and then competed to penetrate the same zona-free bovine oocytes after heterospermic insemination in vitro.

The objective of a second series of experiments was to determine whether the relative penetration rates of spermatozoa from bulls with high or low fertility remained the same after mixing both with low fertility seminal plasma. Spermatozoa from bulls of high or low fertility were mixed with low fertility seminal plasma, homologous or heterologous to the bull of low fertility in each comparison and the relative penetration rates were measured using the zona-free bovine oocyte penetration assay.

\section{Preparation of zona-free bovine oocytes}

The zona-free bovine oocyte assay was performed as described in detail by Henault and Killian (1995). Briefly, oocytes were matured in vitro using the methods of Sirard et al. (1988) and McNutt and Killian (1991).

Ten cumulus-oocyte complexes were matured in each microdrop ( $50 \mu \mathrm{l}$ ) of maturation medium in $60 \mathrm{~mm}$ Petri dishes under heavy paraffin oil. After incubation for $21 \mathrm{~h}$ at $39^{\circ} \mathrm{C}$ in an atmosphere of $5 \% \mathrm{CO}_{2}$ in air, cumulus-oocyte complexes were removed from the maturation microdrops and vortexed in $0.1 \mathrm{ml}$ for $3 \mathrm{~min}$ in $0.5 \mathrm{ml}$ microfuge tubes to remove the cumulus cells. Zonae were removed from cumulus-free, matured oocytes by incubation in $0.1 \%(\mathrm{w} / \mathrm{v})$ pronase (Type XIV-bacterial; Sigma, St Louis, MO) in PBS for 2-5 min with careful observation. No visible zonae remained after this enzyme treatment. Oocytes were then washed three times in low bicarbonate Hepes medium and transferred in groups of 10-50 $\mu \mathrm{l}$ drops of fertilization medium (Bavister et al., 1983) under heavy mineral oil. Dishes were inseminated with $0.25 \times 10^{6}$ spermatozoa and incubated for $12-15 \mathrm{~h}$. After co-incubation with spermatozoa stained with fluorescent dyes, oocytes were washed in low bicarbonate Hepes medium (Bavister et al., 1983). After fixation for $1 \mathrm{~min}$ in neutral buffered formalin and treatment with SLOWFADE antiquenching solution (S-2828A; Molecular Probes Inc., Eugene, OR) oocytes were mounted on slides and stored in a humidified chamber protected from light at $4^{\circ} \mathrm{C}$. Slides were evaluated with an Olympus $\mathrm{BH}-2$ microscope equipped with a $\mathrm{BH} 2-\mathrm{RFC}$ for reflected light fluorescence.

\section{Preparation and capacitation of spermatozoa}

Bulls providing semen for the study were housed at our facility during the course of the experiment. Cull bulls were obtained from three artificial insemination (AI) centres in the northeastern United States. Fertility data for each bull were available from breeding records provided by the AI centres. Data were normalized to account for minor differences among the $\mathrm{AI}$ centres in calculating fertility, and are reported as a percentage point deviation from the average bull fertility of that centre.

Semen was collected from bulls using an artificial vagina. When spermatozoa were to be mixed with seminal plasma from different bulls, spermatozoa in $1 \mathrm{ml}$ of semen were washed once by centrifugation $(500 \mathrm{~g}$ for $10 \mathrm{~min}$ ) in a $1: 10$ ratio with a protein-free, modified Tyrode's medium (MTM; Parrish et al., 1988) containing $1 \mathrm{mg}$ polyvinyl alcohol $\mathrm{ml}^{-1}$ (Bavister, 1981). The remainder of the ejaculate was centrifuged at $2300 \mathrm{~g}$ for $10 \mathrm{~min}$. The supernatant was removed and recentrifuged at $2300 \mathrm{~g}$ for $10 \mathrm{~min}$ to remove remaining spermatozoa from the seminal plasma. The washed spermatozoa were recombined with homologous seminal plasma or heterologous seminal plasma in a ratio approximating that of the original ejaculate and incubated for $30 \mathrm{~min}$ at $37^{\circ} \mathrm{C}$. The pool of low fertility seminal plasma used in the second series of experiments was prepared by combining equal amounts of the seminal plasma from an ejaculate of each of three different subfertile bulls. These bulls ranged in fertility from 18.1 to 11.7 percentage points below the AI centre average and were different from the low fertility bulls providing ejaculated spermatozoa for the experiments. Spermatozoa were washed in MTM $(500 \mathrm{~g}$ for $10 \mathrm{~min})$ and then incubated $\left(50 \times 10^{6}\right.$ cells $\left.\mathrm{ml}^{-\mathrm{I}}\right)$ for $4 \mathrm{~h}\left(39^{\circ} \mathrm{C} ; 5 \% \mathrm{CO}_{2}\right.$ in air) in MTM plus $10 \mu \mathrm{g}$ heparin $\mathrm{ml}^{-1}$. The capacitated spermatozoa were induced to undergo the acrosome reaction by incubation for $10 \mathrm{~min}$ at $39^{\circ} \mathrm{C}$ with $60 \mu \mathrm{g}$ lysophosphatidylcholine $\mathrm{ml}^{-1}$ (LPC; Sigma; McNutt and Killian, 1991), and were then used to inseminate microdrops containing zona-free bovine oocytes. 
Table 1. Heterospermic penetration of oocytes by spermatozoa from bulls of high fertility mixed with homologous seminal plasma (HSP) compared with penetration when the spermatozoa were mixed with seminal plasma from a bull of low fertility (LSP)

\begin{tabular}{|c|c|c|c|c|c|c|c|c|c|c|}
\hline \multicolumn{2}{|c|}{$\begin{array}{c}\text { Source of } \\
\text { spermatozoa } \\
\text { and HSP }\end{array}$} & \multicolumn{2}{|c|}{ Source of LSP } & \multicolumn{2}{|c|}{ Oocytes } & \multirow{2}{*}{$\begin{array}{c}\text { Average } \\
\text { number of } \\
\text { spermatozoa } \\
\text { per fertilized } \\
\text { oocyte }\end{array}$} & \multicolumn{2}{|c|}{$\begin{array}{c}\text { Percentage } \\
\text { of oocytes } \\
\text { with majority }\end{array}$} & \multirow[b]{2}{*}{$\begin{array}{l}\text { Treatment } \\
\text { advantage }\end{array}$} & \multirow[b]{2}{*}{$P$} \\
\hline $\begin{array}{c}\text { Bull } \\
\text { number }\end{array}$ & $\begin{array}{c}\text { Fertility } \\
\text { score }\end{array}$ & $\begin{array}{c}\text { Buil } \\
\text { number }\end{array}$ & $\begin{array}{l}\text { Fertility } \\
\text { score }\end{array}$ & $(n)$ & $\begin{array}{l}\text { Percentage } \\
\text { fertilized }\end{array}$ & & $\begin{array}{c}\text { HSP } \\
\text { spermatozoa }\end{array}$ & $\begin{array}{c}\text { LSP } \\
\text { spermatozoa }\end{array}$ & & \\
\hline 1 & 0.4 & 7 & -6.0 & 29 & 48 & 2.1 & 62 & 38 & HSP & 0.203 \\
\hline 2 & 8.0 & 7 & -6.0 & 52 & 73 & 2.1 & 69 & 31 & HSP & 0.025 \\
\hline 3 & 6.0 & 8 & -3.3 & 35 & 60 & 2.1 & 42 & 58 & LSP & 0.219 \\
\hline 4 & 1.9 & 9 & -6.6 & 19 & 68 & 2.5 & 83 & 17 & HSP & 0.010 \\
\hline 5 & 2.7 & 11 & -6.9 & 25 & 68 & 1.8 & 87 & 13 & HSP & 0.002 \\
\hline 5 & 2.7 & II & -6.9 & 25 & 40 & 1.9 & 78 & 22 & HSP & 0.049 \\
\hline 5 & 2.7 & 10 & -1.6 & 28 & 54 & 1.4 & 42 & 58 & LSP & 0.284 \\
\hline 6 & 2.8 & 11 & -6.9 & 41 & 39 & 2.2 & 67 & 33 & HSP & 0.203 \\
\hline 6 & 2.8 & 10 & -1.6 & 26 & 42 & 1.6 & 73 & 27 & HSP & 0.066 \\
\hline 6 & 2.8 & 12 & -23.4 & 26 & 46 & 1.7 & 64 & 36 & HSP & 0.174 \\
\hline All bulls & & & & 306 & 54 & 1.9 & 70 & 30 & HSP & 0.0001 \\
\hline
\end{tabular}

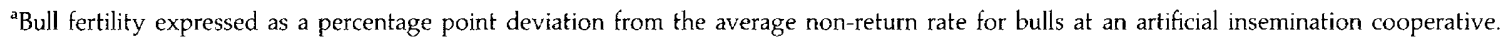

\section{Staining of spermatozoa}

Stock solutions of fluorescein isothiocyanate-isomer I (FITC; Molecular Probes) and tetramethylrhodamine isothiocyanate (TRITC; Molecular Probes Inc.) were prepared following the method of Parrish and Foote (1985). Stock stain solutions were diluted ( $0.1 \mathrm{mg} \mathrm{ml}^{-1}$ ) with phosphate-buffered saline supplemented with glucose (PBSG). All spermatozoa were stained with Hoechst 33342 (Molecular Probes Inc.; $0.5 \mu \mathrm{g} \mathrm{ml}^{-1}$ ), I h before the end of the $4 \mathrm{~h}$ capacitation period to visualize head decondensation and pronuclear development of the spermatozoa. Before dividing the sperm samples for staining and washing, the number of spermatozoa was determined by haemocytometer. FITC $\left(0.5 \mu \mathrm{g} \mathrm{ml}^{-1}\right)$ or TRITC $\left(0.75 \mu \mathrm{g} \mathrm{ml}^{-1}\right)$ was added to the incubation tubes $10 \mathrm{~min}$ before the end of capacitation to distinguish between the treatments. Spermatozoa were then washed twice in fresh MTM and combined in the desired treatment combination at the time of lysophosphatidyl choline incubation. This procedure allowed the identification of the treatment of each spermatozoa that penetrated an oocyte while not affecting sperm motility or the ability to penetrate zona-free bovine oocytes when compared with unstained controls (Henault and Killian, 1995).

\section{Statistical analyses}

McNemar's test, a form of categorical data analysis (Fleiss, 1973), was used to determine whether there was a significant advantage of a particular sperm type when two types of spermatozoa competed to penetrate the same oocytes. McNemar's test enables individual oocytes to be classified according to the type of spermatozoa that penetrated them. The test was conducted by entering data on a grid on which each axis corresponds to increasing numbers of penetrating spermatozoa. This analysis was used to generate $Z$ scores that were evaluated to obtain $P$ values. A $P$ value of $\leq 0.05$ was considered statistically significant.

\section{Results}

Washed spermatozoa from six different bulls with fertilities of 0.4 to 8.0 points above the average for the AI centre of origin were incubated with either homologous seminal plasma, or seminal plasma from a bull of lower fertility to determine the effect of seminal plasma from a bull of low fertility on the fertility in vitro of spermatozoa from a bull of high fertility. Overall, spermatozoa from bulls of high fertility, when incubated in homologous seminal plasma, penetrated significantly more oocytes than when high fertility spermatozoa were incubated in seminal plasma from bulls of low fertility $(P<0.01$; Table 1$)$. Eight of ten comparisons showed that spermatozoa incubated in high fertility seminal plasma had an advantage in penetrating oocytes; however, four of these combinations were not statistically significant. Two comparisons, indicating that high fertility spermatozoa exposed to low fertility seminal plasma penetrated more oocytes than did the same spermatozoa incubated in high fertility seminal plasma, were not statistically significant.

Incubation of low fertility spermatozoa with either low homologous or high fertility seminal plasma indicated an overall improvement in the fertility of the subfertile spermatozoa when incubated with seminal plasma from bulls of high fertility $(P=0.05$; Table 2$)$. Trials were conducted using spermatozoa from bulls ranging in fertility from -1.6 to -23.4 points below the AI centre average. An improvement in fertility was achieved in five out of 10 cases, four of which were statistically significant. Of the remaining five cases, one combination showed no advantage and four showed an advantage in penetrating oocytes for the spermatozoa exposed to 
Table 2. Heterospermic penetration of oocytes by spermatozoa from bulls of low fertility mixed with homologous seminal plasma (LSP) compared with penetration when the spermatozoa were mixed with seminal plasma from a bull of high fertility (HSP)

\begin{tabular}{|c|c|c|c|c|c|c|c|c|c|c|}
\hline \multicolumn{2}{|c|}{$\begin{array}{c}\text { Source of } \\
\text { spermatozoa } \\
\text { and LSP }\end{array}$} & \multicolumn{2}{|c|}{ HSP Source } & \multicolumn{2}{|c|}{ Oocytes } & \multirow{2}{*}{$\begin{array}{c}\text { Average } \\
\text { number of } \\
\text { spermatozoa } \\
\text { per fertilized } \\
\text { oocyte }\end{array}$} & \multicolumn{2}{|c|}{$\begin{array}{c}\text { Percentage } \\
\text { of oocytes } \\
\text { with majority }\end{array}$} & \multirow[b]{2}{*}{$\begin{array}{l}\text { Treatment } \\
\text { advantage }\end{array}$} & \multirow[b]{2}{*}{$P$} \\
\hline $\begin{array}{c}\text { Bull } \\
\text { number }\end{array}$ & $\begin{array}{c}\text { Fertility }^{a} \\
\text { score }\end{array}$ & $\begin{array}{c}\text { Bull } \\
\text { number }\end{array}$ & $\begin{array}{l}\text { Fertility } \\
\text { score }\end{array}$ & (n) & $\begin{array}{l}\text { Percentage } \\
\text { fertilized }\end{array}$ & & $\begin{array}{c}\text { HSP } \\
\text { spermatozoa }\end{array}$ & $\begin{array}{c}\text { LSP } \\
\text { spermatozoa }\end{array}$ & & \\
\hline 7 & -6.0 & I & 0.4 & 33 & 82 & 3.6 & 74 & 26 & HSP & 0.011 \\
\hline 7 & -6.0 & 2 & 8.0 & 60 & 57 & 3.6 & 50 & 50 & NA & 0.500 \\
\hline 10 & -1.6 & 5 & 2.7 & 31 & 55 & 3.0 & 73 & 27 & HSP & 0.035 \\
\hline 10 & -1.6 & 6 & 2.8 & 22 & 45 & 1.4 & 22 & 78 & LSP & 0.038 \\
\hline 8 & -3.3 & 3 & 6.0 & 47 & 47 & 1.9 & 65 & 35 & HSP & 0.090 \\
\hline 11 & -6.9 & 5 & 2.7 & 39 & 69 & 2.0 & 100 & 0 & HSP & $<0.0001$ \\
\hline 11 & -6.9 & 6 & 2.8 & 26 & 88 & 2.9 & 10 & 90 & LSP & $<0.0001$ \\
\hline 12 & -23.4 & 6 & 2.8 & 27 & 67 & 1.9 & 12 & 88 & LSP & $<0.001$ \\
\hline 12 & -23.4 & 5 & 2.7 & 35 & 69 & 2.3 & 77 & 23 & HSP & 0.005 \\
\hline 13 & -15.7 & 6 & 2.8 & 11 & 91 & 3.2 & 25 & 75 & LSP & 0.079 \\
\hline All bulls & & & & 331 & 64 & 2.6 & 56 & 44 & HSP & 0.052 \\
\hline
\end{tabular}

a Bull fertility expressed as a percentage point deviation from the average non-return rate for bulls at an artificial insemination cooperative.

Table 3. Heterospermic penetration of oocytes by high fertility (HF) spermatozoa mixed with low fertility seminal plasma (LFSP) versus low fertility (LF) spermatozoa mixed with homologous low fertility seminal plasma

Source of spermatozoa

\begin{tabular}{|c|c|c|c|c|c|c|c|c|c|c|}
\hline \multicolumn{2}{|c|}{$\mathrm{HF}$} & \multicolumn{2}{|c|}{ LF } & \multicolumn{2}{|c|}{ Source of LFSP } & \multirow{2}{*}{$\begin{array}{c}\text { Fertility of } \\
\text { most spermatozoa } \\
\text { that penetrate } \\
\text { oocytes }\end{array}$} & \multirow[b]{2}{*}{$\begin{array}{c}\text { Number of } \\
\text { oocytes }\end{array}$} & \multirow{2}{*}{$\begin{array}{l}\text { Percentage } \\
\text { of oocytes } \\
\text { fertilized }\end{array}$} & \multirow{2}{*}{$\begin{array}{c}\text { Average number } \\
\text { of spermatozoa } \\
\text { per penetrated } \\
\text { oocyte }\end{array}$} & \multirow[b]{2}{*}{$P$} \\
\hline $\begin{array}{c}\text { Bull } \\
\text { number }\end{array}$ & $\begin{array}{c}\text { Fertility } \\
\text { score }\end{array}$ & $\begin{array}{c}\text { Bull } \\
\text { number }\end{array}$ & $\begin{array}{c}\text { Fertility } \\
\text { score }\end{array}$ & $\begin{array}{c}\text { Bull } \\
\text { number }\end{array}$ & $\begin{array}{c}\text { Fertility } \\
\text { score }\end{array}$ & & & & & \\
\hline 1 & 0.4 & 7 & -6.0 & 7 & -6.0 & LF & 43 & 37 & 3.3 & 0.07 \\
\hline 6 & 2.8 & 13 & -15.7 & 13 & -15.7 & $\mathrm{HF}$ & 19 & 58 & 5.5 & 1.04 \\
\hline 2 & 8.0 & 7 & -6.0 & 7 & -6.0 & LF & 66 & 65 & 4.0 & $<0.01$ \\
\hline 3 & 6.0 & 8 & -3.3 & 8 & -3.3 & LF & 55 & 36 & 1.7 & 0.03 \\
\hline All bulls & & & & & & $\mathrm{LF}$ & 182 & 49 & 3.6 & $<0.01$ \\
\hline
\end{tabular}

${ }^{3}$ Bull fertility expressed as a percentage point deviation from the average non-return rate for bulls at an artificial insemination cooperative.

low fertility homologous seminal plasma. Three of these four cases were statistically significant.

When this experiment was modified so that high, or average, fertility spermatozoa were incubated with low fertility seminal plasma and competed with low fertility spermatozoa incubated in homologous seminal plasma for penetration of oocytes, the low fertility spermatozoa generally had an advantage over the high fertility spermatozoa $(P=0.0012$; Table 3$)$. In three of four cases, the low fertility spermatozoa prevailed over the high fertility spermatozoa. The one comparison in which high fertility spermatozoa penetrated more oocytes was not significant $(P=1.04)$.

The bias imposed by using seminal plasma homologous to only one of the two bulls being compared in each competition represented in Table 3 was eliminated by using a low fertility seminal plasma pool foreign to both bulls being tested. In three of four comparisons (Table 4), the high fertility spermatozoa penetrated more oocytes, but only one of these results was statistically significant. The one case where low fertility spermatozoa prevailed was not statistically significant. The overall advantage of high fertility spermatozoa was also not statistically significant.

\section{Discussion}

It is known that seminal plasma proteins become associated with sperm membranes at the time of ejaculation (Isojima $e t$ al., 1987; Aumüller et al., 1988, 1989; Kameda et al., 1991; Autiero et al., 1991; Manjunath et al., 1994). Attempts to remove these proteins from rabbit spermatozoa, using high salt concentrations (Brackett and Oliphant, 1975; Oliphant, 1976), indicated that the association of some seminal plasma proteins to the sperm membranes is quite strong. Bovine seminal vesicle proteins exhibit phospholipid-mediated binding to the sperm surface at ejaculation and can be successfully displaced only 
Table 4. Heterospermic penetration of oocytes by high fertility (HF) spermatozoa mixed with pooled low fertility seminal plasma versus low fertility (LF) spermatozoa mixed with heterologous pooled low fertility seminal plasma

\begin{tabular}{|c|c|c|c|c|c|c|c|c|}
\hline \multicolumn{4}{|c|}{ Source of spermatozoa } & \multirow{3}{*}{$\begin{array}{c}\text { Fertility of } \\
\text { most spermatozoa } \\
\text { that penetrate } \\
\text { oocytes }\end{array}$} & \multirow[b]{3}{*}{$\begin{array}{c}\text { Number of } \\
\text { oocytes }\end{array}$} & \multirow[b]{3}{*}{$\begin{array}{l}\text { Percentage } \\
\text { fertilized }\end{array}$} & \multirow{3}{*}{$\begin{array}{c}\text { Average number } \\
\text { of spermatozoa } \\
\text { per penetrated } \\
\text { oocyte }\end{array}$} & \multirow[b]{3}{*}{$P$} \\
\hline \multicolumn{2}{|c|}{$\mathrm{HF}$} & \multicolumn{2}{|c|}{ LF } & & & & & \\
\hline $\begin{array}{c}\text { Bull } \\
\text { number }\end{array}$ & $\begin{array}{c}\text { Fertility } \\
\text { score }\end{array}$ & $\begin{array}{c}\text { Bull } \\
\text { number }\end{array}$ & $\begin{array}{c}\text { Fertility } \\
\text { score }\end{array}$ & & & & & \\
\hline 4 & 1.9 & 12 & -23.4 & $\mathrm{HF}$ & 24 & 42 & 1.7 & 0.10 \\
\hline 4 & 1.9 & 11 & -6.9 & $\mathrm{HF}$ & 24 & 42 & 1.6 & 0.26 \\
\hline 5 & 2.7 & 11 & -6.9 & $\mathrm{HF}$ & 35 & 46 & 1.9 & 0.05 \\
\hline 5 & 2.7 & 10 & -1.6 & LF & 18 & 72 & 1.8 & 0.12 \\
\hline All bulls & & & & $\mathrm{HF}$ & 102 & 48 & 1.8 & 0.12 \\
\hline
\end{tabular}

${ }^{a}$ Bull fertility expressed as a percentage point deviation from the average non-return rate for bulls at an artificial insemination cooperative.

after incubation with phosphorylcholine (Manjunath et al., 1994). This strong binding may explain our inability to improve the fertility of ejaculated spermatozoa from subfertile bulls consistently by washing and mixing them with seminal plasma from bulls of high fertility. The results of the ten comparisons showed an advantage in oocyte penetration by spermatozoa incubated in high fertility seminal plasma in four of the seven combinations in which a particular type of spermatozoa had a statistically significant advantage in oocyte penetration.

It is also clearly apparent that the bull providing the high fertility seminal plasma to combine with low fertility spermatozoa can profoundly affect the results. For example, seminal plasma from high fertility bull 5 significantly improved the oocyte penetration rates of spermatozoa from three different bulls of low fertility. However, seminal plasma from high fertility bull 6 failed to improve the ability to penetrate oocytes of spermatozoa from the same three bulls of low fertility and an additional bull of low fertility.

Prior exposure of spermatozoa to accessory sex gland components at ejaculation may compromise later attempts to replace membrane-bound seminal components by mixing with seminal plasma from another bull. This conclusion is strongly supported by other studies carried out in our laboratory using bovine epididymal spermatozoa (Henault $e t$ al., 1995). When epididymal spermatozoa from bulls of low fertility were mixed with accessory sex gland fluid from bulls of high fertility, ability to penetrate oocytes was significantly improved when comparisons were made with the same spermatozoa mixed in low fertility accessory sex gland fluid. These results, taken with the results of the present study, show that our ability to change the fertility of ejaculated bovine spermatozoa by exposure to seminal plasma is more limited than when similar experiments are carried out with epididymal spermatozoa and accessory sex gland fluid.

The observation that high fertility spermatozoa mixed with low fertility seminal plasma had significantly fewer penetrations than did high fertility spermatozoa incubated in homologous seminal plasma or low fertility spermatozoa mixed with homologous low fertility seminal plasma are important. These results may indicate that low fertility seminal plasma contains antifertility factors that have a greater negative effect on high fertility spermatozoa than on low fertility spermatozoa. Previous exposure of low fertility spermatozoa to negative factors in their own seminal plasma may preclude further reduction in fertility after exposure to foreign low fertility seminal plasma. This conclusion is supported by the experiments using pooled low fertility seminal plasma foreign to the subfertile bulls being tested. Although the differences between bulls of high or low fertility were no longer significant, high fertility spermatozoa probably had decreased fertility. This conclusion can be made because the penetration assay used has been shown to detect small differences in fertility of ejaculated spermatozoa from bulls of high and low fertility (Henault and Killian, 1995).

Although antifertility factors have been found in seminal plasma of many species (Chang, 1957; Dukelow et al., 1967; Reddy et al., 1979), reports of differences between seminal plasma from individuals of high and low fertility are limited. Protein differences have been detected when the seminal plasma of bulls of high fertility was compared with that of bulls of low fertility (Killian et al., 1993). Alterations in seminal plasma protein distribution between fertile and subfertile individuals have also been noted in humans (Sadowski and Rogers, 1985) and differences in heparin-binding proteins in seminal plasma have been correlated with fertility in bulls (Kandell et al., 1992). It is possible that there are fertility or antifertility factors in seminal plasma and that they bind to spermatozoa at the time of ejaculation. These seminal plasma constituents may be difficult to remove from the spermatozoa by routine washing since the results presented here show that prior exposure to a particular type of seminal plasma appears to predetermine the fertility of ejaculated spermatozoa unlike cauda epididymal spermatozoa (Henault et al., 1995). In addition, it does not appear that the fertility of ejaculated spermatozoa can be significantly changed by simple washing and exposure to seminal plasma of contrasting fertility, with the possible exception of the lowering effect on fertility of low fertility seminal plasma.

The exact components of seminal plasma that are responsible for the effects observed are yet to be identified. This study, however, presents convincing evidence that seminal plasma is important in determining the fertility of ejaculated spermatozoa and that these determinants differ among bulls. 
This work was supported by USDA Grant 93-37203-9069. Appreciation is expressed to the staff of the Dairy Breeding Research Center for technical assistance and to the USDA Animal Hormone Program and National Institute of Arthritis, Metabolism and Digestive Diseases for providing gonadotrophins used in the maturation of bovine oocytes. The authors thank Y. Akin of the Department of Statistics at Penn State University for assistance with the statistical analyses. They are also indebted to Atlantic Breeders Cooperative, Sire Power, Inc., Eastern Artificial Insemination Cooperative, Tri State Breeders Inc., and 21st Century Genetics for providing the bulls and the in vivo fertility data used in this study.

\section{References}

Audhya T, Reddy J and Zaneveld LJD (1987) Purification and partial chemical characterization of a glycoprotein with antifertility activity from human seminal plasma Biology of Reproduction 36 511-521

Aumüller G, Vesper M, Seitz J, Kemme M and Scheit KH (1988) Binding of a major secretory protein from bull seminal vesicles to bovine spermatozoa Cell and Tissue Research 252 377-384

Aumüller G, Huntemann S, Larsch KP and Seitz J (1989) Seminal proteins binding to spermatozoa. In Developments in Ultrastructure of Reproduction pp 241-248 Alan R Liss Inc., New York

Autiero M, Abrescia P and Guardiola J (1991) Interaction of seminal plasma proteins with cell surface antigens: presence of a CD4-binding glycoprotein in human seminal plasma Experimental Cell Research 197 268-271

Bavister BD (1981) Substitution of a synthetic polymer for protein in a mammalian gamete culture system Journal of Experimental Zoology 217 $45-51$

Bavister BD, Leibfried ML and Lieberman G (1983) Development of preimplantation embryos of the golden hamster in a defined medium Biology of Reproduction 28 235-247

Brackett BG and Oliphant G (1975) Capacitation of rabbit spermatozoa in vitro Biology of Reproduction 12 260-274

Chang MC (1957) A detrimental effect of seminal plasma on the fertilizing capacity of sperm Nafure $179258-259$

Chow PH, Pang SF, Ng KW and Wong TM (1986) Fertility, fecundity, sex ratio and the accessory sex glands in male golden hamsters International journal of Andrology 9 312-320

Corteel JM (1980) Effets du plasma séminal sur la survie et la fertilité des spermatozoïdes conservés in vitro Reproduction, Nutrition, Développement 20 $1111-1123$

Curry PT and Atherton RW (1990) Seminal vesicles: development, secretory products, and fertility Archives of Andrology 25 107-113

Dott HM, Harrison RAP and Foster GCA (1979) The maintenance of motility and the surface properties of epididymal spermatozoa from bull, rabbit and ram in homologous seminal and epididymal plasma Journal of Reproduction and Fertility 55 113-124

Dukelow WR, Chernoff HN and Williams WL (1967) Properties of decapacitation factor and presence in various species Joumal of Reproduction and Fertility 14 393-399

Fleiss JL (1973) Statistical Methods for Rates and Proportions pp 72-91. John Wiley and Sons, New York

Gaur RD and Talwar GP (1973) Isolation of a factor from human seminal plasma that promotes fertilization Nature 244 450-451
Gaur RD and Talwar GP (1975) Further studies on the fertility-promoting factor from human seminal plasma International Journal of Fertility 20 133-136

Henault MA and Killian GJ (1995) Effect of sperm preparation and bull fertility on in vitro penetration of zona-free bovine oocytes Theriogenology $\mathbf{4 3}$ 739-749

Henault MA, Killian GJ, Kavanaugh JF and Griel LC (1995) Effect of accessory sex gland fluid from bulls of differing fertilities on the ability of cauda epididymal sperm to penetrate zona-free bovine oocytes Biology of Reproduction 52 390-397

Isojima S, Kameda K, Tsuji Y, Shigeta M, Ikeda Y and Koyama K (1987) Establishment and characterization of a human hybridoma secreting monoclonal antibody with high titers of sperm immobilizing and agglutinating activities against human seminal plasma Journal of Reproductive Immunology 10 67-78

Iwamoto T and Gagnon C (1988) Purification and characterization of a spermmotility inhibitor in human seminal plasma Journal of Andrology 9 377-383

Iwamoto T, Tsang A, Luterman M, Dickson J, deLamirande E, Okuno M, Mohri H and Gagnon C (1992) Purification and characterization of a sperm motilitydynein ATPase inhibitor from boar seminal plasma Molecular Reproduction and Development 31 55-62

Kameda K, Takada Y, Hasegawa A, Tsuji Y, Koyama K and Isojima S (1991) Sperm immobilizing and fertilization-blocking monoclonal antibody $2 \mathrm{C} 6$ to human seminal plasma antigen and characterization of the antigen epitope corresponding to the monoclonal antibody Journal of Reproductive Immunology 20 27-41

Kandell RL, Bellin ME, Hawkins HE and Ax RL (1992) Bull fertility was related to distributions of heparin-binding proteins in sperm membranes and seminal plasma Journal of Andrology 13 Supplement 130

Killian GJ, Chapman DA and Rogowski LA (1993\} Fertility-associated proteins in Holstein bull seminal plasma Biology of Reproduction 49 1202-1207

McNutt TL and Killian GJ (1991) Influence of bovine follicular and oviductal fluids on sperm capacitation in vitro Journal of Andrology 12 244-252

Manjunath P, Chandonnet L, Leblond E and Denoyers L (1994) Major proteins of bovine seminal vesicles bind to spermatozoa Biology of Reproduction $\mathbf{4 9}$ $27-37$

Oliphant G (1976) Removal of sperm-bound seminal plasma components as a prerequisite to induction of the rabbit acrosome reaction Fertility and Sterility $2728-38$

Pang SF, Chow PH and Wong TM (1979) The role of the seminal vesicle, coagulating glands and prostate glands on the fertility and fecundity of mice Journal of Reproduction and Fertility 56 129-132

Parrish JJ and Foote RH (1985) Fertility differences among male rabbits determined by heterospermic insemination of fluorochrome-labelled spermatozoa Biology of Reproduction 33940949

Parrish JJ, Susko-Parrish JL, Winer MA and First NL (1988) Capacitation of bovine sperm by heparin Biology of Reproduction 38 1171-1180

Queen K, Dhabuwala CB and Pierrepoint CG (1981) The effect of the removal of the various accessory sex glands on the fertility of male rats Journal of Reproduction and Fertility 62 42.3-426

Reddy JM, Stark RA and Zaneveld LJD (1979) A high molecular weight antifertility factor from human seminal plasma Journal of Reproduction and Fertility 57 437-446

Sadowski T and Rogers BJ (1985) Two-dimensional electrophoretic patterns of seminal plasma proteins from fertile and infertile men Biology of Reproduction 32 Supplement 1102

Sirard MA, Parrish JJ, Ware CB, Leibfried-Rutledge ML and First NL (1988) The culture of bovine oocytes to obtain developmentally competent embryos Biology of Reproduction 39 546-552 